Vol. $7-\mathrm{N}^{\mathrm{o}} 28$

Enero - junio, año 2021

pp. 225-238

\title{
Filosofía y Movimiento ${ }^{1}$
}

\author{
Esaú Ricardo Páez Guzmán² \\ Universidad Pedagógica y Tecnológica de Colombia \\ Jorge Alberto Valcárcel Guzmán ${ }^{3}$ \\ Universidad Pedagógica y Tecnológica de Colombia
}

Este informe deriva de un proyecto de investigación de producción radial y audiovisual, que tiene como objetivo acercar la filosofía a la comunidad a través de productos de apropiación social de conocimiento, tales como pósteres y ponencias presentadas en eventos académicos internacionales.

2 Doctor en Ciencias de la Educación de la Universidad Pedagógica y Tecnológica de Colombia, y Magister en Gobierno Municipal de la Universidad Externado de Colombia.

Correo electrónico: esau.paez@uptc.edu.co

3 Estudiante de la Licenciatura en Filosofía de la Universidad Pedagógica y Tecnológica de Colombia.

Correo electrónico: jorge.valcarce101@uptc.edu.co 


\title{
Resumen
}

Este trabajo es el resultado de un proceso formativo realizado por estudiantes de la Licenciatura en Filosofía de la UPTC. Tiene como finalidad acercar la filosofía a diferentes ámbitos sociales mediante propuestas como la construcción de un discurso filosófico accesible al público en general, y la creación de un proceso formativo en investigación que pueda concretarse en una práctica de comunicación abierta, más allá de los límites y modos de conversación propios de la filosofía universitaria. Es por esta razón que se busca divulgar la filosofía en los medios de comunicación, como una manera de incorporar y aprovechar al interior de las dinámicas tecnológicas actuales la imagen, el audio y el video para mostrar la potencialidad del discurso filosófico, sin olvidar la importancia de que éste sea comprensible y accesible para todos.

Palabras clave: apropiación de conocimiento, difusión filosófica, discurso filosófico.

\begin{abstract}
This project is the result of a research training process carried out by students of the Bachelor's Degree in Philosophy at the UPTC. It aims to bring philosophy closer to different social environments through proposals such as the construction of a philosophical discourse accessible to the general public, and the creation of a formative process in research that can be concretized in a practice of open communication, beyond the limits and modes of conversation typical of university philosophy. It is for this reason that we seek to disseminate philosophy in the media, as a way to incorporate and take advantage of the current technological dynamics of image, audio and video to show the potential of philosophical discourse, without forgetting the importance of making it understandable and accessible to all.
\end{abstract}

Keywords: appropriation of knowledge, philosophical diffusion, philosophical discourse. 


\section{El problema de enseñar filosofía}

Parte de la tradición filosófica (introducida desde su formalización institucional) ha llevado a estudiar el discurso filosófico, sus autores y problemas, cronológicamente, es decir en sentido lineal (Foucault, 1999); en un orden establecido de problemáticas, perspectivas y filósofos, dando a entender que para comprender por ejemplo a Aristóteles es estrictamente necesaria la compresión de Platón o, en igual caso, que para entender el pensamiento de Kant hay que conocer primero las obras de Descartes y Hume.

Una de las tareas del licenciado en filosofía es ser intermediario de la complejidad discursiva propia de ésta y recurrir a sus conceptos como herramientas útiles para dialogar y preguntar. Por esta razón se puede pensar que la formación tradicional imposibilita, en alguna medida, el acercamiento al discurso filosófico de personas que no están inmersas en el ámbito académico y que precisan de un medio para poder hacerlo (Deleuze y Guattari, 1978, p. 178). Se hace necesario, entonces, romper con esta linealidad para hacer accesibles y discutibles los conceptos y problemas filosóficos.

Los cambios en el modo de presentar el conocimiento (su producción y circulación a través de la historia), las nuevas condiciones de la economía mundial y las transformaciones técnicas y científicas que han generado la revolución tecnológica, exigen innovar en la práctica misma de enseñar y, puntualmente, promueven una transformación del discurso filosófico para alcanzar el objetivo de impactar en diversos contextos, más allá de la simple práctica característica de la rigurosidad del estudio universitario, con un enfoque que reflexione en torno a situaciones y experiencias cotidianas. Los rituales propios de la actividad académica universitaria (sus personajes, sus tiempos, sus ritmos), en los cuales los discursos academicistas atraviesan las prácticas y se vuelven acciones en las que se conjuga una manera atávica de la institución universitaria, afectan las formas y los procedimientos de la institución y los direccionamientos de otros discursos en los diferentes espacios educativos (Páez y Montero, 2014).

El lenguaje filosófico construye sus cimientos en conceptos y teorías, genera el encuentro con personas del común y con la vida misma (Lyotard, 1987). Con esta idea, el proyecto que se expone en este informe busca difundir el lenguaje filosófico de una forma que permita reivindicar la importancia de la filosofía en la academia, posibilitando acercar los conceptos y su aplicación 
a la vida cotidiana de quienes no hacen parte de aquella por la creencia de que la filosofía es un discurso para letrados y eruditos. La filosofía puede descubrirse en la vida diaria, es una manera de encarar el mundo, de situarse ante un problema, abordarlo, entenderlo y otorgarle sentido.

Este proyecto busca plantear diferentes maneras de transmitir el discurso filosófico, pensando en las transformaciones globales que ponen en primer plano algunos problemas que ameritan su reflexión conceptual y práctica. Cuando el lenguaje filosófico se hace más complejo, su dificultad nos conduce a pensar en el ciudadano común a quien este lenguaje, por tradición y por efectos del ritual mismo de las prácticas universitarias, parece un discurso lejano y oscuro. ¿Cómo enfrentar la problemática de que generalmente la filosofía no aborda el discurso común para entrar en el espacio "de la teoría" y "de los conceptos"?

\section{Alternativas para la difusión del discurso filosófico}

En la actualidad los sistemas educativos ${ }^{4}$ son el eje central del proceso de formación académica. Tales sistemas están obligados a crear herramientas que permitan una aprehensión del conocimiento. Sin embargo, los sistemas educativos están detenidos en el tiempo, ya que fueron creados para responder a problemáticas ya no vigentes. Mark Prensky afirma que la escuela ha olvidado su deber, que consiste en dar luz en medio del contexto actual en el que los jóvenes son volátiles y buscan comprender rápidamente todo, acogiendo o desechando lo que llame su atención (2010, p. 18). Los sistemas educativos han direccionado la academia hacia los contenidos que se deben cursar, y éstos, a su vez, obedecen a intereses particulares del sistema económico vigente. Los avances tecnológicos, que se pensó que ayudarían a emancipar de este control, se han encargado más bien de perpetuar esta situación.

Con el desarrollo de nuevas tecnologías de la información y comunicación pareciera que para el proceso de aprendizaje ya no fuera necesario un docente; se evidencia un cambio: los estudiantes aprenden en las redes. Ken Robinson afirma la necesidad de que los sistemas educativos sean innovadores y se actualicen, pues son anacrónicos y ya no ofrecen respuestas a problemas actuales. Se ha pensado sólo en la necesidad de aumentar los estándares, pero sin perder esa asincronía (Robinson, 2015). Robinson sostendrá también

${ }_{4}$ Modelos particulares para la enseñanza y el aprendizaje. 
que todas las áreas del conocimiento poseen igual valor, en contra de que la jerarquización de las áreas educativas ha clasificado lo que debería ser aprendido con mayor rigor. Es por ello que las dinámicas educativas son transformadas para responder a necesidades económicas y organizacionales que dejan atrás a las humanidades y a las artes. Estamos inmersos en una economía de servicios; en un sistema de educación industrial en el que se debe tener cierto nivel de educación para obtener un puesto de trabajo, obligados a pensar en que la economía crezca. Robinson plantea entonces que la educación debe optar por comprehender el mundo que le rodea y forjar un sentimiento de identidad cultural. En esta tónica, hay una disparidad entre las necesidades educativas, económicas, culturales e individuales, pues se ha dejado atrás el mundo de los otros, la convivencia, la historia, las artes, la filosofía, etc. Las dinámicas educativas que responden a necesidades económicas ejercen una profunda influencia negativa sobre las formas de pensar y actuar de los educandos, en la medida en que entorpecen un discernimiento crítico al enfocarse en la búsqueda de resultados tangibles, en su mayoría exentos de reflexión intrapersonal ${ }^{5}$. Es por esto que la idea de que la educación se enfoque exclusivamente en la transmisión de información atenta contra el sentido originario de ésta como promotora del desarrollo artístico, cultural e intelectual.

Lo descrito anteriormente nos conduce a pensar cómo atraer a personas que no son cercanas al ámbito de la filosofía hacia programas con contenido filosófico. A su vez, introducir a la filosofía en los medios masivos de comunicación revela otra problemática: la paradoja del uso del lenguaje al momento de conversar con nuestros oyentes (Pérez-Latre, 2000). Esta es la razón por la cual nuestro proyecto pretende encontrar un equilibrio entre la presentación de contenidos filosóficos y los medios visuales y radiales, sin perder, precisamente, el rigor del ámbito filosófico. Es importante preguntar cómo se logra un punto de convergencia entre la filosofía y un oyente no especializado en ella. Son la difusión, el lenguaje filosófico y el diálogo con el otro, por tanto, nuestras preocupaciones principales. ¿Existe entonces la posibilidad de desarrollar conceptos filosóficos a través de la radio y la transmisión de imágenes, para generar en la comunidad la capacidad de preguntarse por sí mismos y/o por la sociedad en la que habitan?

5 Preguntarnos por nosotros mismos: quiénes somos y qué hacemos en el lugar en que habitamos. 
Son propósitos fundamentales, entonces, mantener un espacio de difusión de discursos filosóficos en la emisora universitaria de la UPTC dirigido al público en general; construir discursos filosóficos que puedan traducir la complejidad de los conceptos y la reflexión filosófica a un lenguaje fluido y comprensible para dicho público, mediante las técnicas de locución radial ${ }^{6}$; emitir un programa de radio que se ocupe de diversos conceptos filosóficos y pueda impactar en la comunidad, enfocando la atención de ésta en la filosofía en tanto disciplina preocupada por problemas cercanos a la condición de los seres humanos: la violencia, el amor, el arte, la música, la risa, el dolor, la muerte, los placeres, etc.; recopilar y publicar el material de los programas de radio como apoyo pedagógico para la enseñanza de la filosofía; crear un programa audiovisual que permita emitir el discurso filosófico a un público no académico:

Los medios masivos de comunicación surgieron en el interior de una experiencia económico política que despolitiza la esfera de lo público y lo popular para acosarla bajo el término "masa" y su connotación de multitud informe e ignorante, la historia nos puede pensar como parte de "la masa", e incluso podemos serlo, pero lo que en este momento mundial lo que realmente interesa es un acoplo a los cambios tecnológicos y sociales que se ven diariamente (Sierra, 1988, p. 4).

Los programas de contenido filosófico -tanto visuales como radiales- son vistos en el medio académico como espacios de apoyo a la práctica del aprendizaje de la filosofía, porque ayudan a comprender cómo el discurso filosófico influye en la vida cotidiana. Como ejemplo pueden ser descritos los siguientes programas radiales y visuales:

1. La caverna de Platón: espacio que surge en el 2014 en radio enlace de Madrid, y en el que se ofrece orientación en torno a lecturas de Filosofía, siendo "un lugar de encuentro para todos los interesados por la filosofía, desde la enseñanza secundaria hasta la enseñanza superior".

2. Filosofía en la Onda: un programa de radio sobre práctica filosófica, emitido por primera vez en mayo del 2013, en un programa piloto que duró media hora. Desde entonces ha estado en el aire durante tres temporadas, ampliándose a una hora y media de emisión semanal en directo. Este

${ }_{6}^{6}$ Expresarse de forma clara, logrando que la narración sea lo más natural posible, haciendo énfasis en palabras o frases en los momentos correctos para generar una atracción en el oyente. 
programa radial utiliza la filosofía como pretexto para hablar de diferentes temas de la academia.

3. Filosóficamente hablando: programa radial emitido desde comienzos de 2012 en Radio Oasis Salamanca (España), que cuenta con un espacio en el que se "lanzan reflexiones y preguntas a los oyentes" sobre temas relacionados con la filosofía.

\section{Realización de los libretos}

El objetivo de este proyecto responde a la siguiente pregunta: ¿es posible difundir el pensamiento filosófico utilizando los medios de comunicación? Y, siendo más específicos, ¿existe la posibilidad de acercar los conceptos filosóficos a un público amplio a través de herramientas como los programas radiales y audiovisuales?

El Grupo de Investigación "Filosofía, Educación y Pedagogía" viene trabajando de tiempo atrás la manera de ampliar las formas de dar a conocer el lenguaje de la filosofía; cuestión en la que se enmarca el proyecto expuesto en este informe. El intento de traducir los conceptos filosóficos a un lenguaje menos académico exige una labor sistemática de rastreo bibliográfico, elaboración de fichas y notas, discusión en grupo y puesta a prueba en la escritura de guiones para programas radiales y audiovisuales, buscando materializar esta idea como un proyecto enfocado en su sentido práctico, lo que supone una metodología que hace énfasis en los procesos a partir de situaciones concretas. En este caso, el punto de partida será el acumulado de experiencias que el equipo de estudiantes ha venido sumando en su proceso de formación investigativa en el grupo.

Los programas procuran realizar un acercamiento de la filosofía a la cotidianidad mediante problemáticas, autores y conceptos que en muchas ocasiones presentan alto grado de dificultad. Cada programa presenta en su estructura una serie de piezas musicales, sonidos o temas sonoros que en la emisión radial se denominan cortinas, y que sirven como ambientación para el cambio de voz o de tema en la grabación, permitiéndole al oyente adentrarse con mayor facilidad y agrado a la temática tratada. Se busca que las pistas utilizadas estén relacionadas con el tema correspondiente a cada programa, que generen la atmósfera que se quiere transmitir durante la grabación, y que permitan acercar al oyente a una idea o concepto filosófico. Cada libreto presenta una "melodía" particular. 
En la siguiente tabla se pueden observar algunos de los libretos del programa Psicofonías del más acá:

Tabla 1. Ejemplos de libretos del proyecto Filosofía y Movimiento

\begin{tabular}{|c|c|c|}
\hline Título & Desarrollo & Ambientación \\
\hline $\begin{array}{l}\text { El Gliglico } \\
\text { (2016) }\end{array}$ & $\begin{array}{l}\text { Amalaba, noema, clémiso, hidromurias, ambonios, incopelusas, } \\
\text { relamar. Palabras psicofónicas que sólo pueden ser de Julio } \\
\text { Cortázar, recordándonos que los actos de amor se codifican } \\
\text { en voces de los amantes. Voces traídas por nuestros nuevos } \\
\text { integrantes Tatiana Reyes y Daniel Virviescas, quienes en este } \\
\text { primer programa del año se unen a psicofonías del más acá con } \\
\text { Cortázar y su lenguaje glíglico para los amantes traficantes de } \\
\text { palabras con sabor a noemas y clémisos. Hoy, querido sordente, } \\
\text { hablaremos del glíglico. Bienvenidos. } \\
\text { Y como el tema que nos convoca es Julio Cortázar y el lenguaje } \\
\text { glíglico para los amantes. Ahora los invitaremos a imaginar: una } \\
\text { muchacha que baila con el viento. Su vestido va y viene como una } \\
\text { ola. En sus labios una gota de luz tiembla, y los pliegues del viento } \\
\text { dejan contemplar sus largas piernas, suaves y blancas, talladas } \\
\text { con precisión. Sus ojos se quiebran y brillan. Ella hace un gesto } \\
\text { pícaro y usted se queda perplejo, ni siquiera una sola palabra } \\
\text { rueda por su lengua. Nada. Silencio. } \\
\text { Quizás, la imagen de la muchacha en su cabeza despierte las } \\
\text { argulias corpándose hacia el paso de su trusfénide, y extasiado } \\
\text { de bruscas córtides, haga temblar sus profundos melundios. } \\
\text { Pero no lo puede decir. Ni una sola de estas palabras le recobra el } \\
\text { aliento. La muchacha que baila con el viento y usted han quedado } \\
\text { incomunicados porque no conocen el glíglico. } \\
\text { Dejando a la muchacha que baila con el viento, ahora es necesario } \\
\text { entender de mejor manera cuál es el origen del glíglico. Para ello, } \\
\text { es preciso recordar que en } 1962 \text { fue publicada una compilación } \\
\text { de hojas bastante sospechosas, bautizadas con el nombre de } \\
\text { "Rayuela". El desequilibrado escritor argentino, conocido no } \\
\text { tan comúnmente como Julio Cortázar, fue acusado de cometer } \\
\text { uno de los crímenes más insólitos contra la literatura. Pues el } \\
\text { escandaloso libro se había autodenominado antinovela y atentaba } \\
\text { el orden y el buen escribir. }\end{array}$ & $\begin{array}{l}\text { Summertime- } \\
\text { Charlie Parker }\end{array}$ \\
\hline $\begin{array}{l}\text { El realismo } \\
\text { Social en la } \\
\text { revolución de } \\
\text { Octubre } \\
(2017)\end{array}$ & $\begin{array}{l}\text { "Si tu esposa te ha traicionado, } \\
\text { Alégrate de que te haya traicionado a ti y no a la patria " } \\
\text { Esta frase pertenece a un clásico, al maestro ruso de cuento Antón } \\
\text { Chejov, quien logró plasmar profundamente la naturaleza humana } \\
\text { en sus obras literarias provocando risas a través de las lágrimas, } \\
\text { siendo que el pueblo ruso por muchos años soportó las injurias de } \\
\text { un imperio, que aunque esplendoroso, condujo a la mayoría de su } \\
\text { gente hasta el límite de la pobreza. }\end{array}$ & $\begin{array}{c}\text { Marche Slave- } \\
\text { Tchaikovsky }\end{array}$ \\
\hline
\end{tabular}




\begin{tabular}{|c|c|c|}
\hline & $\begin{array}{l}\text { Hoy en Psicofonías del más acá, se abordará (en conmemoración } \\
\text { los cien años de la revolución rusa) la influencia de la literatura en } \\
\text { la Revolución de Octubre; Ios hechos que marcaron los eventos } \\
\text { revolucionarios en Rusia en el año de 1917. Tendremos un } \\
\text { acercamiento a cómo el sometimiento del gobierno monárquico } \\
\text { terminó por condenar su propio derrocamiento a causa de las } \\
\text { inhumanas condiciones que se presentaron en el pueblo ruso; } \\
\text { sometimientos que evocarían autores como Gógol, Gorki, Tolstói } \\
\text { y Dostoievski. } \\
\text { A mitad del siglo XIX el pueblo ruso había vivido más de tres } \\
\text { siglos sometido a un régimen monárquico, con condiciones de } \\
\text { desigualdad mayores que en el resto de Europa. Pero, a pesar } \\
\text { de ello, se lleva a cabo una revolución que marcaría un nuevo } \\
\text { panorama para el mundo entero. Nos preguntamos entonces ¿qué } \\
\text { circunstancias sobrevinieron para que el pueblo ruso, tras épocas } \\
\text { de hambre e inequidad, por fin se revelara? }\end{array}$ & \\
\hline $\begin{array}{c}\text { Los otros } \\
\text { planetas de } \\
\text { Saint-Exupery } \\
\text { (2019) }\end{array}$ & $\begin{array}{l}\text { Antoine de Saint-Exupéry fue un aviador que jamás olvidó el niño } \\
\text { que habitó en él. Escribió una obra que, aunque está dirigida a los } \\
\text { más chicos, está llena de pasajes y reflexiones que conmueven } \\
\text { incluso al más 'adulto'. Este pequeño libro está dedicado, con } \\
\text { algunas salvedades, a un adulto que sufre. Saint- Exupéry lo } \\
\text { aclara. En la primera parte de su obra nos narra el recorrido } \\
\text { que tuvo que realizar el Principito desde el Asteroide B612 hasta } \\
\text { nuestro planeta. Sin embargo, parece que no nos cuenta el paso } \\
\text { de este pequeño hombrecillo por otros tres curiosos planetas. Hoy } \\
\text { en Psicofonías del Más Acá le contaremos este parte del trayecto } \\
\text { hasta ahora desconocida. Bienvenidos. } \\
\text { El octavo planeta tenía una gran dimensión. Era veinte veces } \\
\text { más grande que su pequeño Asteroide. El Principito calculó que } \\
\text { en él tardaría aproximadamente tres cuartos de hora en ocurrir } \\
\text { una puesta de sol, sin embargo, tuvo la fortuna de llegar en el } \\
\text { momento propicio. Al detenerse observó un fornido hombre, muy } \\
\text { elegante, con un traje azul y una corbata carmesí reluciente. Un } \\
\text { poco más adelante corrían dos hombrecillos a los que apenas } \\
\text { alcanzó a ver. } \\
\text { - ¿Por qué corren? - Preguntó. } \\
\text { El hombre que divisaba el horizonte no le prestó atención. } \\
\text { - ¿Por qué corren? - Repitió el Principito que jamás renunciaba a } \\
\text { una pregunta después de haberla formulado. } \\
\text { - Porque se los ordené - Respondió el hombre al percatar la } \\
\text { presencia del forastero. } \\
\text { - ¿Y por qué se lo ordenaste? } \\
\text {-Porque soy el general. Además, al otro lado del planeta está } \\
\text { el enemigo y hay que aprovechar la poca luz del ocaso para } \\
\text { someterlo. }\end{array}$ & $\begin{array}{c}\text { Música } \\
\text { Instrumental } \\
\text { Francesa }\end{array}$ \\
\hline
\end{tabular}

Páez, E. y Valcárcel Guzmán, J. (2021). Filosofía y Movimiento.

Cuestiones de Filosofía, 7 (28), 225-238 


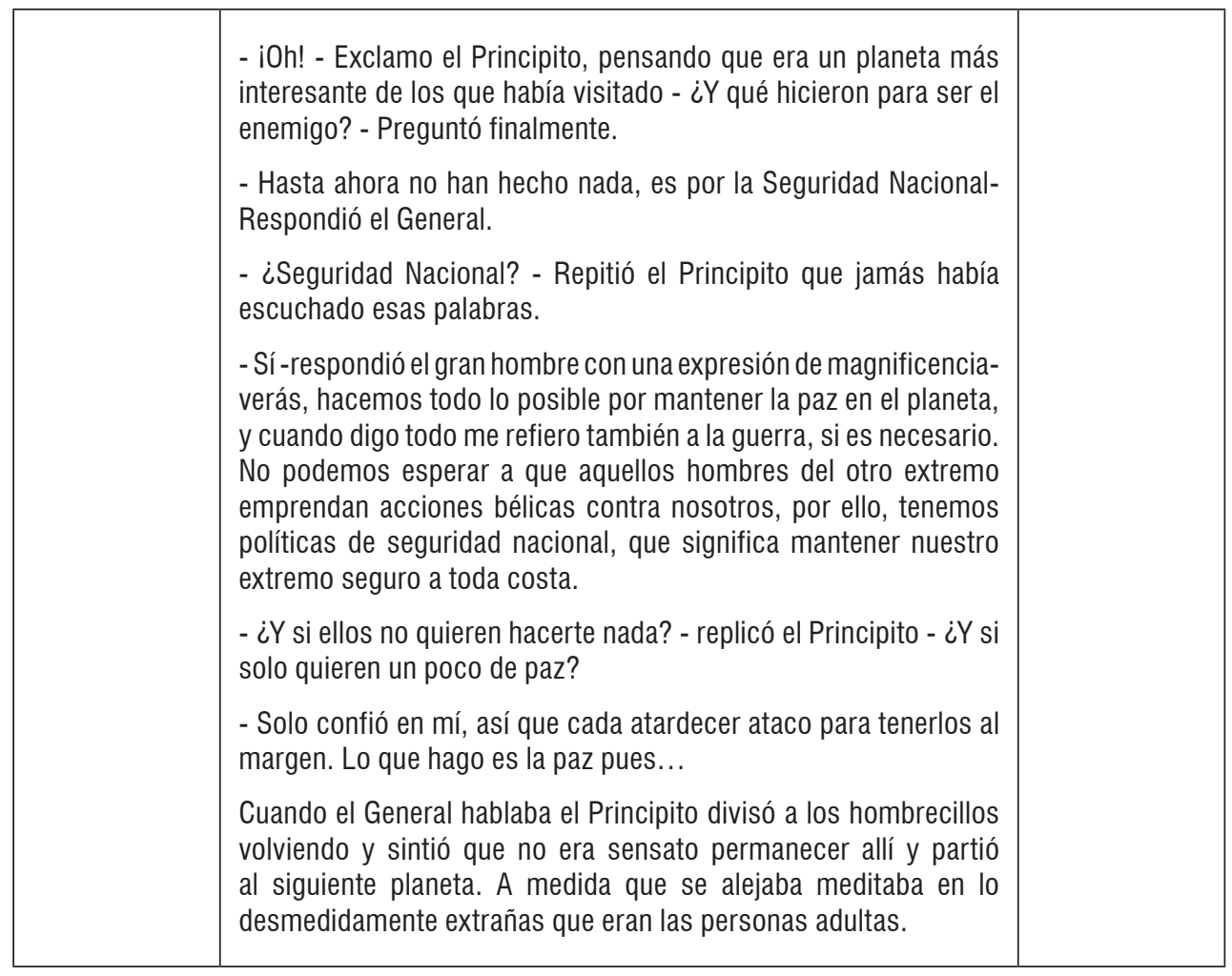

Pensar la enseñanza de la filosofía a través de programas que se ocupen de cuestiones cotidianas, haciendo uso de los medios de comunicación masiva y buscando incitar el pensar crítico, es el propósito de proyectos como "Filosofía y Movimiento": lograr una relación entre el oyente y la reflexión filosófica. Dicha experiencia filosófica se preocupa por acercar puntos de vista distintos al campo de la educación y la enseñanza de la filosofía: construir una forma distinta de filosofar. Esto conlleva investigar el nivel de influencia de los programas de contenido filosófico emitidos a través de las Tecnologías de la Información y la Comunicación, con el fin de incitar una experiencia filosófica individual y colectiva al brindar contenidos concebidos como un campo abierto de posibilidades y de respuesta a preguntas o situaciones del diario vivir, tales como: ¿por qué somos como somos? ¿Por qué hablamos como hablamos? etc. De esta manera se pretende dar a la filosofía el lugar que le pertenece, y ese lugar es estrictamente hablando, la cotidianidad.

\section{Resultados de la investigación}

El objetivo del proyecto ha sido acercar la filosofía a la comunidad en general y lograr un primer acercamiento a ella mediante el desarrollo de temas, 
conceptos y problemas filosóficos que puedan ser comprendidos mediante una experiencia colectiva. Para ello consideramos que los programas radiales -y ahora audiovisuales- son más que una herramienta tecnológica: pueden ser un espacio de encuentros filosóficos, de reflexión, en el que se amplíen las posibilidades de acercar la filosofía a la comunidad. Actualmente existen en el mundo varias propuestas similares que permiten acercarse a la filosofía, tales como series, programas radiales y audiovisuales como: Filosofia de Contrabando de la Universidad de La Salle en Colombia, CuriosaMente del Estudio Haini SC en México o Filosofía en 8bits de Wisecrack en Estados Unidos. Sin embargo, el proyecto "Filosofía y Movimiento" indaga acerca de cómo la imagen puede generar una relación entre la filosofía y la comunidad, intentando transformar un fenómeno como la visualización de un video en un impulso para mostrar un programa con contenido reflexivo, en el que se introduzcan conceptos filosóficos que motiven al receptor a ser más crítico con su entorno. En el prefacio de La sociedad del espectáculo Guy Debord cita a Feuerbach, quien afirma: "Y sin duda nuestro tiempo (...) prefiere la imagen a la cosa, la copia al original, la representación a la realidad, la apariencia al ser" (1994, p. 7). Para Debord la imagen es ahora el modo predilecto de representar las condiciones, ideales y valores de la cultura contemporánea. La imagen se ha adentrado tan fuertemente en la existencia de cada uno de nosotros, que ya es casi imposible apartarse de su influencia: las acciones de los individuos del siglo XXI están supeditadas en todo momento a las imágenes digitales; su uso masivo ha banalizado casi por completo todos los campos del actuar humano. Sin embargo, lo que se pretende ahora con la creación de programas visuales que aborden ideas filosóficas y que sean proyectados en los medios masivos de comunicación, no se hace con el objetivo de banalizar el discurso filosófico, sino como una manera de adaptarnos a las nuevas condiciones del siglo XXI.

Con la experiencia construida a lo largo de estos años, hemos aprendido que la difusión del lenguaje filosófico es baja debido a la complejidad discursiva de éste. Es por esto que es necesario aprovechar las posibilidades que nos brindan las Tecnologías de la Información y de la Comunicación a la hora de acercarnos a la comunidad y aprovechar estas tecnologías para difundir la reflexión filosófica. Para esto es importante acudir a diversos medios de comunicación mediante los cuales se interactúe con distintas comunidades académicas y sociales (tal como se muestra a continuación). Este proyecto plantea, por tanto, acercar la filosofía a todo tipo de público y ofrecer la posibilidad de que cualquier persona, sin pertenecer a la academia, acceda al lenguaje filosófico. 
Tabla 2. Productos desarrollados

\begin{tabular}{|c|c|c|c|c|c|c|c|c|}
\hline Productos & $\mathbf{2 0 1 3}$ & $\mathbf{2 0 1 4}$ & $\mathbf{2 0 1 5}$ & $\mathbf{2 0 1 6}$ & $\mathbf{2 0 1 7}$ & $\mathbf{2 0 1 8}$ & $\mathbf{2 0 1 9}$ & Total \\
\hline Radiales & 18 & 5 & 20 & 28 & 23 & 17 & 21 & 132 \\
& & & & & & & & \\
Visuales & - & - & - & - & - & 1 & 9 & 10 \\
Conversatorios & - & - & - & - & - & 1 & 2 & 3 \\
\hline
\end{tabular}

\section{Conclusiones}

Nuestro proyecto busca difundir la filosofía a todo tipo de público, sin pretender que los oyentes se vinculen formalmente con alguna institución educativa en particular. De esto surge la idea de apropiarse de diversos medios de comunicación y de la organización de conversatorios en los cuales se pueda hablar de filosofía sin recurrir al discurso especializado ni a las prácticas académicas más comunes (sesiones magistrales y lectura de artículos). Teniendo en cuenta esta experiencia se llega a las siguientes conclusiones:

1. Es necesario aprovechar las amplias posibilidades que ofrece la difusión del conocimiento a través de las Tecnologías de la Información y de la Comunicación, dado que esto favorece la divulgación del proyecto en la medida en que éste se hace accesible a un auditorio mucho más amplio.

2. Difundir contenidos en medios masivos de comunicación ha incremento la visibilidad del proyecto y ha generado una respuesta positiva de parte de la comunidad que ha escuchado o visualizado los programas.

3. Traducir la complejidad del discurso filosófico es la labor más compleja del proyecto. Es por esta razón que se deben evitar las malinterpretaciones entre lo que sostiene un autor determinado y aquello que se afirma acerca de éste en los programas.

4. Utilizar obras y figuras literarias nos ha permitido explicar las abstracciones propias de la filosofía con una mayor facilidad (ver tabla 1.), puesto que el 
uso de expresiones coloquiales y la recreación de situaciones y diálogos (propios de la literatura) facilitan comprender con mayor claridad muchos de los conceptos propios de la filosofía.

A futuro es importante hacer un seguimiento técnico del número de espectadores por programa, ya que esto nos daría un estimativo del alcance que está teniendo el proyecto. Calcular el número de oyentes permitiría hacer un seguimiento de si los cambios estructurales y discursivos de los libretos (además de lograr un aumento en la audiencia) han sido realmente significativos para motivar la reflexión filosófica.

\section{Referencias}

Debord, G. (1995). La sociedad del espectáculo. Santiago de Chile: Naufragio. Deleuze, G. y Guattari, F. (1978). Mil Mesetas. Valencia: Pre-textos.

Foucault, M. (1999). El orden del Discurso. Barcelona: Tusquets.

López, L., y Virviescas, D. (2017). Filosofía y Movimiento. Un acercamiento de la filosofía a la comunidad (Memorias de Evento). I Encuentro Internacional de Investigación Universitaria (ENIIU), pp. 213-214. http://rdigitales.uptc.edu.co/ memorias/index.php/eniiu/ped_practicas/ paper/viewFile/2513/2572

Lyotard, J. (1987). La condición postmoderna. Madrid: Cátedra.

Prensky, M. (2010). Nativos e inmigrantes digitales. Madrid: SEK.

Pérez-Latre, F. (2000). Planificación y gestión de medios publicitarios. Barcelona: Ariel.

Páez, E., y Montero, M. (2014). Educación y Pedagogía. Pasajes, encuentros y conversaciones. Tunja: Universidad Pedagógica y Tecnológica de Colombia.

Robinson, K. (2015). Escuelas creativas. La revolución que está transformando la educación (L. Arónica, Ed.). Barcelona: Penguin Random House.

Rojas, S. (2004). Los ruidos del sonido. Notas para una filosofía de la música. Revista Musical Chilena, 58 (201). pp. 7-33. http://dx.doi.org/10.4067/ S0716-27902004020100001 
Sierra, F. (1988). Filosofía de la comunicación: Entorno a los medios (Memorias de Evento). Signo y Pensamiento V Congreso Internacional de filosofía latinoamericana. Filosofía de la educación en América Latina, pp. 137-144. http://revistas.javeriana.edu.co/index.php/ signoypensamiento/article/viewFile/3505/2807 